\title{
Pulmonary hypertension: diagnostic approach and optimal management
}

\author{
Nathan Hambly MD, Fahad Alawfi MD, Sanjay Mehta MD
}

Competing interests: See end of article.

This article has been peer reviewed.

\section{Correspondence to:} Sanjay Mehta,

sanjay.mehta@lhsc.on.ca

CMAJ 2016. DOI:10.1503 /cmaj.151075
$\mathrm{P}$ ulmonary hypertension $(\mathrm{PH})$ is a serious and progressive lung disease, defined by elevation of pulmonary arterial pressure. Affected patients are often disabled by symptoms of dyspnea, fatigue, syncope and chest pain, and they are at high risk of right ventricular failure and premature death. The prevalence of PH was estimated in one study at 97 cases per million, which suggests that at least 3000 and as many as 10000 Canadians may be affected. ${ }^{1}$ Because $\mathrm{PH}$ is uncommon and there is limited awareness, most patients receive the diagnosis late in the disease course, which results in delayed initiation of effective therapies, greater patient suffering and potentially worse long-term clinical outcomes, including survival. ${ }^{2}$

Accurate diagnosis and appropriate treatment of $\mathrm{PH}$ are associated with important clinical, functional and quality-of-life benefits and often longer survival. Here, we outline an approach

\section{Box 1: Evidence used in this review}

We searched MEDLINE (1980 to present) and the Cochrane Database of Systematic Reviews using a variety of search terms, including "pulmonary hypertension," "pulmonary arterial hypertension," "chronic thromboembolic pulmonary hypertension" and "pulmonary endarterectomy." We restricted our search to articles published in English. We included randomized controlled trials, relevant review articles, and consensus or clinical practice guideline documents. We reviewed the reference lists of pertinent articles and guideline documents for additional articles.

\section{KEY POINTS}

- Pulmonary hypertension is an uncommon but serious progressive disease of the lung circulation characterized by increased pulmonary arterial pressure and complicated by right ventricular failure and premature death.

- Early and accurate diagnosis depends upon clinical suspicion in patients at high risk and those with unexplained symptoms such as dyspnea, edema and syncope.

- In every patient with pulmonary hypertension, chronic thromboembolic disease should be ruled out as a cause, given that surgical pulmonary endarterectomy is a potential cure for chronic thromboembolic pulmonary hypertension.

- A greater understanding of the pathobiology of pulmonary arterial hypertension, achieved through research over 20 years, has led to nine Health Canada-approved medications that have improved symptoms, functional capacity, quality of life and survival for many patients. for the accurate diagnosis and optimal management of patients with $\mathrm{PH}$. The clinical and diagnostic strategies described are supported by expert consensus. ${ }^{1,3}$ The approach to medical management is based on strong evidence from randomized controlled trials (RCTs) and metaanalyses (Box 1).

\section{What causes PH?}

Pulmonary hypertension occurs for many reasons, most commonly as a complication of cardiopulmonary or systemic disease. The World Health Organization (WHO) has classified PH into five groups on the basis of distinct pathophysiology, pulmonary hemodynamics and management strategies (Box 2). ${ }^{1,4}$ WHO group 1 refers to pulmonary arterial hypertension, characterized by the progressive remodelling, narrowing and obliteration of small pulmonary arteries due to proliferation of smooth muscle and endothelial cells, vascular wall inflammation and fibrosis. ${ }^{5}$

WHO group 2 (related to disorders of the left side of the heart) and group 3 (associated with lung disease or chronic hypoxemia) are the most frequent types of PH. Patients typically have advanced chronic cardiopulmonary disease, with the presence of $\mathrm{PH}$ resulting in more severe symptoms, worse health-related quality of life and poorer survival. ${ }^{6,7}$ For example, the presence of PH (mean pulmonary arterial pressure $\geq 25 \mathrm{~mm} \mathrm{Hg}$ ) in patients with chronic obstructive pulmonary disease was associated with increased 5-year mortality (relative risk [RR] 2.2, 95\% confidence interval [CI] 1.1-3.8). ${ }^{8}$ Similarly, among 1094 patients with various cardiac conditions, the presence of WHO group $2 \mathrm{PH}$ was associated with markedly worse survival $(p<0.001){ }^{9}$

Modest evidence from uncontrolled case series and a few small RCTs suggests that PH-targeted therapies have inconsistent and limited effects on pulmonary hemodynamics and exercise capacity, with no improvement in clinical outcomes for patients with WHO group 2 or 3 PH. ${ }^{1}$ Thus, international guidelines ${ }^{1}$ and the Choosing Wisely cam- 
paign ${ }^{10}$ have strongly recommended against the use of PH-targeted therapies in such patients. Management should instead be directed at optimization of the underlying cardiopulmonary condition, especially to address fluid overload and hypoxemia. ${ }^{1}$ Pulmonary hypertension is typically of only mild to moderate severity in WHO groups 2 and 3, and the presence of severe $\mathrm{PH}$ or right ventricular failure (or both) in patients with cardiopulmonary disease warrants assessment for potentially treatable causes and referral to an expert centre.

WHO group 4 chronic thromboembolic $\mathrm{PH}$ (CTEPH) is related to chronic thromboembolic obstruction of the pulmonary arteries following multiple or recurrent pulmonary emboli. Acute $\mathrm{PH}$ and right ventricular dysfunction are common in acute pulmonary embolism, being present in about half of affected patients. ${ }^{3}$ However, these acute abnormalities resolve in most patients who receive appropriate treatment with systemic anticoagulation. As a result, the cumulative incidence of CTEPH following acute symptomatic pulmonary embolism is $1 \%-4 \% .{ }^{11,12}$ A retrospective multivariable analysis of three large studies of acute pulmonary embolism showed that the strongest predictive factors for future CTEPH were unprovoked pulmonary embolism (RR $18,95 \%$ CI 1.8 to $>100$ ) and right ventricular dysfunction on computed tomographic pulmonary angiography or echocardiography (RR 5.9, 95\% CI 1.819). ${ }^{13}$ Importantly, one-third to one-half of patients with CTEPH have no prior history of venous thromboembolism, such that CTEPH cannot be excluded on the basis of clinical history alone. ${ }^{14}$

WHO group 5 includes $\mathrm{PH}$ related to a variety of medical conditions, such as sarcoidosis and hematologic or metabolic disorders, in which the mechanisms of $\mathrm{PH}$ are poorly understood or multifactorial. For these patients, the focus is on optimal management of the underlying condition. However, for some patients with severe $\mathrm{PH}$ or right ventricular failure (e.g., those with sarcoid-associated $\mathrm{PH}$ ), treatment with PH-targeted medications may be considered, according to limited evidence..$^{15}$ Conversely, targeted medications are contraindicated for most patients with $\mathrm{PH}$ secondary to sickle cell disease, given a lack of benefit and more frequent vaso-occlusive crises. ${ }^{16}$

\section{What are the presenting features?}

The clinical features of PH include nonspecific symptoms of dyspnea and pedal edema, subtle physical signs such as a loud pulmonic compo- nent of the second heart sound $\left(\mathrm{P}_{2}\right)$ and characteristic abnormalities on common noninvasive investigations (Box 3). The onset is insidious, and patients first experience dyspnea and fatigue only with substantial exertion. The symptoms typically worsen over a period of weeks to months until most patients experience limitations with any exertion and during daily activities. Progressive $\mathrm{PH}$ and resulting right ventricular failure are manifested by exertional lightheadedness, syncope and chest pain.

The signs on physical examination are subtle. A systematic review showed that the most specific and thus greatest predictive finding of $\mathrm{PH}$ was a loud $\mathrm{P}_{2}$ (positive likelihood ratio 56.4, 95\% CI 7.9-401.7). ${ }^{17}$ In a prospective cohort study, however, the same authors found that an accentuated $\mathrm{P}_{2}$ was only weakly predictive (positive likelihood ratio $1.9,95 \%$ CI $1.2-3.1) .{ }^{17}$ The diagnostic strength of other signs is poor, as most features have a negative likelihood ratio approximating 1. Characteristic features on common noninvasive investigations can also indicate the presence of $\mathrm{PH}$, any of which should prompt further diagnostic work-up (Box 3).

Pulmonary hypertension is typically diagnosed in patients between 30 and 60 years of age, but it can affect patients of any age and is two to three times more common among women. ${ }^{1,18}$ Greater vigilance is recommended for patients at high risk, such as those with scleroderma, who have a lifetime cumulative risk of $15 \%$ to $20 \% .^{19}$

Box 2: World Health Organization clinical classification of pulmonary hypertension ${ }^{1}$

Group 1: Pulmonary arterial hypertension

- Idiopathic (formerly primary pulmonary hypertension)

- Heritable (for example, BMPR2 mutations)

- Induced by drugs or other toxins (e.g., anorexigens, cocaine)

- Associated with connective tissue disease

- Associated with HIV infection

- Associated with congenital heart disease

- Associated with portal hypertension

- Associated with schistosomiasis

Group 2: Pulmonary hypertension due to left-sided heart disease

- Examples: systolic LV failure, LV diastolic dysfunction, valvular diseases

Group 3: Pulmonary hypertension due to lung disease or hypoxia (or both)

- Examples: chronic obstructive pulmonary disease, interstitial lung disease, sleep apnea

Group 4: Chronic thromboembolic pulmonary hypertension (CTEPH)

Group 5: Pulmonary hypertension with unclear multifactorial mechanisms

- Examples: chronic hemolytic anemia, sarcoidosis, chronic renal failure

Note: $B M P R 2$ = gene for bone morphogenetic protein receptor type $2, L V=$ left ventricle. 


\section{What is the diagnostic approach for a patient with suspected PH?}

A rigorous diagnostic approach (Appendix 1, available at www.cmaj.ca/lookup/suppl/doi:10.1503/ cmaj.151075/-/DC1) will define the presence, cause and severity of $\mathrm{PH}$, ensuring that patients can benefit optimally from available management options. ${ }^{1}$ All patients with suspected $\mathrm{PH}$ should undergo transthoracic echocardiography. ${ }^{1}$ This method estimates right ventricular systolic pressure and assesses the right ventricle for $\mathrm{PH}$-related functional abnormalities (e.g., systolic dysfunction) and structural changes (e.g., right ventricular dilatation); it can also identify cardiac causes of PH. Right ventricular systolic pressure estimated by Doppler echocardiography, a surrogate for systolic pulmonary arterial pressure (which requires invasive right-heart catheterization), is usually below $40 \mathrm{~mm} \mathrm{Hg}$ in healthy adults. ${ }^{20}$ However, echocardiographic estimation of right ventricular systolic pressure is subject to substantial inaccuracy because of technical limitations and operator inexperience. Studies have consistently shown that, in about $50 \%$ of cases, right ventricular systolic pressure determined by echocardiography differs by more than $10 \mathrm{~mm} \mathrm{Hg}$ from pulmonary hemodynamic measurements obtained during right-heart catheterization. ${ }^{21-23}$ As such, measures of right ventricular systolic pressure should not be viewed in isolation but rather should be integrated into a complete echocardiographic evaluation.

International guidelines recommend annual echocardiography and pulmonary function tests

Box 3: Clinical features and laboratory findings (noninvasive investigations) suggestive of pulmonary hypertension ${ }^{1,4}$

\section{Clinical features}

- Symptoms: unexplained dyspnea, fatigue, exertion intolerance, edema, syncope, chest pain

- Physical findings: elevated jugular venous pressure, peripheral edema, accentuated pulmonic component of second heart sound $\left(P_{2}\right)$, pansystolic murmur at left lower sternal border (tricuspid regurgitation)

- Risk factors and relevant medical history: connective tissue disease, liver cirrhosis, HIV infection, moderate-to-severe cardiac disease, moderate-tosevere lung or respiratory disease or hypoxemia (or both), personal or family history of deep vein thrombosis or pulmonary embolism

\section{Findings on noninvasive investigations}

- Electrocardiography: right axis deviation, RV hypertrophy and strain, RA dilatation ("P pulmonale")

- Chest radiography: enlarged hilar pulmonary arteries, enlarged cardiac silhouette (especially RV on lateral view)

- Pulmonary function tests: reduction in diffusing capacity for carbon monoxide

- Echocardiography: increased RV systolic pressure, RV hypertrophy, enlarged RV and RA, RV systolic dysfunction

Note: $\mathrm{RA}=$ right atrium, $\mathrm{RV}=$ right ventricle. to screen for asymptomatic $\mathrm{PH}$ in all patients with scleroderma. ${ }^{1,19}$ The cost-effectiveness of screening in the absence of symptoms relative to symptom-based detection remains uncertain.

Clinically important $\mathrm{PH}$ is likely when right ventricular systolic pressure is above $50 \mathrm{~mm} \mathrm{Hg}$ or there are other echocardiographic findings suggestive of right ventricular failure (Box 3 ). ${ }^{1}$ In patients with these echocardiographic features, careful clinical assessment and standard investigations to diagnose the specific cause of PH are recommended. ${ }^{1}$ Ultimately, most patients should be referred to an expert centre to undergo right-heart catheterization, the diagnostic gold standard. The hemodynamic definition of $\mathrm{PH}$ is an increased mean pulmonary arterial pressure (i.e., $\geq 25 \mathrm{~mm} \mathrm{Hg}$ ), ${ }^{1}$ which is common to all five of the WHO groups (Box 2).

\section{WHO Group 1 pulmonary arterial hypertension: a diagnosis of exclusion}

Most patients with $\mathrm{PH}$ have WHO group 2, 3 or 4 $\mathrm{PH}$. As such, these disease entities must be specifically investigated and excluded before pulmonary arterial hypertension (WHO group 1) can be diagnosed. In addition to a mean pulmonary arterial pressure of $25 \mathrm{~mm} \mathrm{Hg}$ or higher, a definitive hemodynamic diagnosis of pulmonary arterial hypertension also requires that the patient have normal pulmonary artery wedge pressure and elevated pulmonary vascular resistance (> 3 Wood units). ${ }^{1}$ During right-heart catheterization, selected patients with pulmonary arterial hypertension should undergo acute vasoreactivity testing with inhaled nitric oxide, to identify those belonging to the subset of $15 \%$ of patients with acute vasodilator responsiveness, ${ }^{24}$ for whom treatment with calcium-channel blockers (e.g., diltiazem, amlodipine) is strongly recommended $^{1,25}$ (Figure 1).

\section{WHO Group 4 CTEPH: a critical diagnosis to consider}

Many clinical experts consider CTEPH, a common and curable condition, the most important type of PH. Accordingly, Canadian ${ }^{3}$ and international $^{1}$ guidelines recommend a rigorous diagnostic approach to assess for the presence of CTEPH in all patients with PH. These recommendations are based on expert consensus that there is a high likelihood of clinical benefit and little potential harm to or burden for the patient if CTEPH is diagnosed, despite a lack of evidence directly addressing this issue.

An initial nuclear ventilation-perfusion lung scan is strongly recommended, ${ }^{1,3,26}$ because normal results on scanning effectively exclude CTEPH with very high negative predictive value 
(96\%-99\%). ${ }^{26}$ An abnormal result on ventilationperfusion scanning necessitates further pulmonary angiographic imaging (Appendix 1). The guidelines do not recommend routine screening for CTEPH after pulmonary embolism because of a lack of evidence. ${ }^{1,3}$ Definitive characterization of the severity and anatomic extent of CTEPH usually requires right-heart catheterization for direct hemodynamic measurements and invasive pulmonary angiography. These procedures are essential before a patient with CTEPH can be considered for potentially curative pulmonary endarterectomy.

\section{What is the optimal management of WHO group 1 pulmonary arterial hypertension?}

Optimal management, including medical therapy for pulmonary arterial hypertension, depends on accurate diagnosis and a dedicated team consisting of knowledgeable physicians and allied health care providers (e.g., nurses, pharmacists) who are familiar with the available PH-targeted medications, their benefits and adverse effects, and potential drug-drug interactions. Over the past 20 years, an increased understanding of the pathobiology of pulmonary arterial hypertension has fostered the development and widespread availability of many $\mathrm{PH}$-targeted medications, including nine in Canada. On the basis of consensus among Canadian and international experts, it is strongly recommended that patients with pulmonary arterial hypertension be managed at a centre with demonstrated expertise. ${ }^{1}$ Canada has a network of 15 such expert centres, which are based in academic medical institutions across the country (www.phacanada.ca, www. livingwithph.ca). This centralization of care in expert centres and the institution of PH-targeted therapies have been associated with improvements in survival. Uncontrolled studies of data from several large international registries suggest that the average survival after diagnosis of pulmonary arterial hypertension has increased to more than $7-10$ years. ${ }^{2}$

Despite these advances, however, there is still no cure for pulmonary arterial hypertension. For patients and their immediate caregivers (e.g., spouse, parents, children), living with this condition represents a substantial physical, emotional, social and often financial burden. The goal of management is the alleviation of this burden, which requires disease education, psychosocial support and targeted medical therapies to improve the patient's symptoms, functional capacity and health-related quality of life; to prevent progression of the pulmonary arterial hypertension (e.g., right ventricular failure, admission to hospital, need for lung transplant); and to prolong survival. A stepwise comprehensive approach to management, based on the regular, rigorous assessment of severity of $\mathrm{PH}$ and right ventricular failure, is essential to achieve these goals (Figure 1).

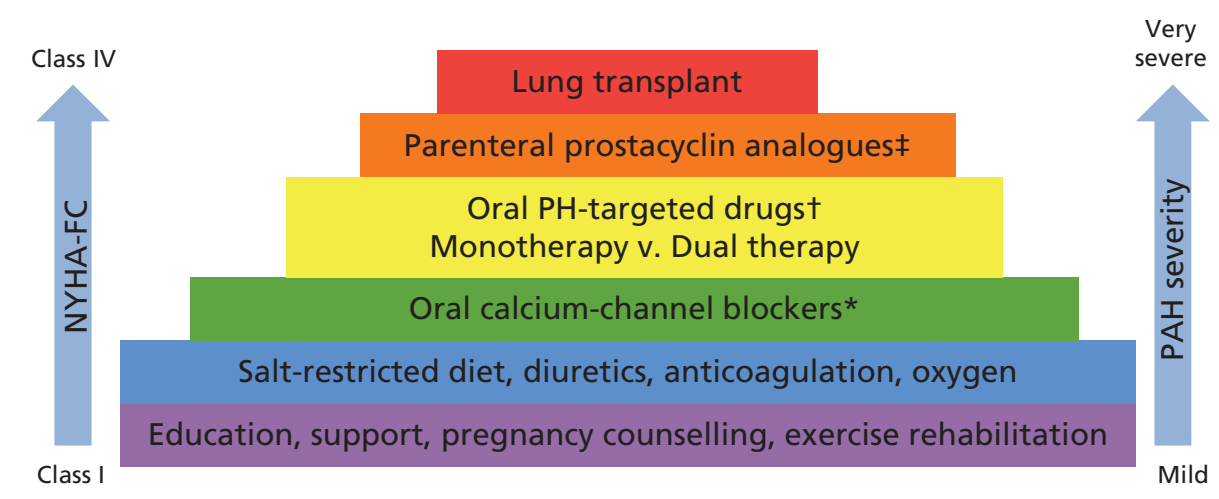

Figure 1: Stepwise approach to managing pulmonary arterial hypertension (PAH) at Canadian expert centres, starting from bottom of the pyramid (based on the evidence described in Box 1). * Recommended only for patients whose pulmonary arterial hypertension meets specific criteria (idiopathic, heritable or drug-induced) and is identified as responsive to vasodilators by acute vasoreactivity testing during rightheart catheterization. tOptions are phosphodiesterase type 5 inhibitors (PDE-5i; sildenafil, tadalafil) and soluble guanylate cyclase stimulators (sGC-S; riociguat), which improve signalling through the nitric oxide pathway; endothelin receptor antagonists (ERAs; bosentan, ambrisentan, macitentan), which block the action of endothelin-1; and a prostacyclin receptor agonist (selexipag), which addresses endogenous prostacyclin deficiency. Dual oral targeted combination therapy consists of one medication from the ERA family and another medication from either the PDE-5i family or the SGC-S family. fOptions include the synthetic prostacyclin analogues epoprostenol (intravenous) and treprostinil (intravenous or subcutaneous). NYHA-FC = New York Heart Association functional class, $\mathrm{PH}=$ pulmonary hypertension. 


\section{General measures}

In dealing with any complex, serious or fatal illness, education of patients and their caregivers about the disease, its potential complications and disease-specific management can reduce anxiety and may improve adherence to medication therapy and lifestyle recommendations, health-related quality of life and clinical outcomes.

Exercise rehabilitation training is recommended on the basis of two RCTs, which reported better exercise capacity (improvement in mean 6 -min walk distance, by $56-111 \mathrm{~m}$; $p \leq 0.002)$ and health-related quality of life (e.g., improvements in six of eight domains on the 36-item Short Form Health Survey and both physical and mental summary scores; $p<0.05) .27,28$ However, there are limited data on the optimal type, intensity and duration of exercise training or the level of supervision required for safety.

In patients with right ventricular failure, a sodium-restricted diet and the judicious use of diuretics can control fluid overload, often reducing the size of the right ventricle and improving its function. International guidelines suggest systemic anticoagulation for selected patients with pulmonary arterial hypertension (e.g., idiopathic, heritable and drug-induced forms) to improve survival, on the basis of moderate evidence from a prospective cohort study and several uncontrolled case series. ${ }^{1,29}$ Similarly, according to expert consensus, continuous long-term oxygen therapy is strongly recommended for patients with pulmonary arterial hypertension and resting hypoxemia (e.g., partial pressure of oxygen in arterial blood $<60 \mathrm{~mm} \mathrm{Hg}$ ) ${ }^{1}$

The fluid overload and hemodynamic alterations encountered during pregnancy can be catastrophic for women with pulmonary arterial hypertension. Older case series reported nearuniversal fetal loss and maternal mortality of at least $50 \%$ from worsening right ventricular failure. ${ }^{1,30,31}$ More recently, case reports and uncontrolled series have described successful management of pulmonary arterial hypertension through pregnancy and normal delivery. ${ }^{30}$ Nevertheless, guidelines based on expert consensus still advise avoidance or early termination of pregnancy in women with pulmonary arterial hypertension. ${ }^{1}$ There is little agreement on the most appropriate method of birth control. Although barrier methods are safe, their limited practical efficacy often necessitates dual protection with both barrier and oral contraception. Progesterone-only medical contraceptives are effective and avoid the thrombotic risk of estrogen-containing agents. Estrogenonly or combined estrogen-progesterone contraceptives are acceptable for patients with pulmonary arterial hypertension who are also receiving anticoagulants. Intrauterine devices are effective, but their insertion may lead to a vasovagal reaction, which may be poorly tolerated by those with severe pulmonary arterial hypertension. ${ }^{31}$

\section{PH-targeted medications}

Pulmonary arterial hypertension is defined by disturbed cardiopulmonary hemodynamics; the primary goals of medical management are thus to reduce the severity of the pulmonary hemodynamic abnormality and to improve right ventricular function. Treatment-related improvements in cardiopulmonary hemodynamics (e.g., improved cardiac output or index), clinical symptoms as reflected by New York Heart Association (NYHA) functional class, and functional or exercise capacity (e.g., 6-min walking distance) are associated with benefits in terms of health-related quality of life and evidence of greater clinical stability. Indeed, many PH-targeted medications reduce the risk of clinical worsening, including decreased rate of hospital admission, delayed need for lung transplant and increased long-term survival (Appendix 2, available at www.cmaj.ca/ lookup/suppl/doi:10.1503/cmaj.151075/-/DC1).

Vasodilator therapy with a high dose of calcium-channel blocker is strongly recommended for a small number of select patients with pulmonary arterial hypertension who exhibit marked acute vasodilator responsiveness on vasoreactivity testing during right-heart catheterization, despite only weak data from uncontrolled cohort studies. ${ }^{1,25}$ This recommendation is based on substantial long-term cardiopulmonary hemodynamic improvements, including reductions in mean ( \pm standard deviation) pulmonary arterial pressure (from $54 \pm 10$ $\mathrm{mm} \mathrm{Hg}$ to $35 \pm 7 \mathrm{~mm} \mathrm{Hg}$ ) and pulmonary vascular resistance (from $10.3 \pm 4.6$ Wood units to $4.4 \pm 1.7$ Wood units), as well as an increase in the cardiac index (from $2.8 \pm 0.6 \mathrm{~L} / \mathrm{min}$ per $\mathrm{m}^{2}$ to $3.7 \pm 0.9 \mathrm{~L} / \mathrm{min}$ per $\left.\mathrm{m}^{2}\right)($ all $p<0.001){ }^{25}$ Moreover, clinical benefits include dramatically better survival (97.4\% survival at mean followup of $7.0 \pm 4.1 \mathrm{yr} ; p<0.001)$ in patients with idiopathic pulmonary arterial hypertension treated with these drugs. ${ }^{25}$ It should be emphasized, however, that most patients with idiopathic pulmonary arterial hypertension do not exhibit vasodilator responsiveness and that the use of calcium-channel blockers is contraindicated in such patients because of a greater risk of death.

For patients with pulmonary arterial hypertension, pulmonary artery endothelial cell dysfunction is thought to be a key pathophysiologic mechanism contributing to disease onset and progression. 
This endothelial dysfunction is characterized by decreased synthesis of nitric oxide and prostacyclin and increased production of endothelin-1.32 Available Health Canada-approved PH-targeted medications exert their beneficial effects through one of these three signalling pathways (Appendix 2, Figure 1). Parenteral administration of prostacyclin analogues (e.g., epoprostenol, treprostinil) or the oral prostacyclin receptor agonist selexipag addresses endogenous prostacyclin deficiency. Excess endothelin-1 action through binding to endothelin receptors is inhibited by endothelin receptor antagonist medications (e.g., ambrisentan, bosentan, macitentan). Nitric oxide deficiency is addressed by enhancing its signalling pathway with either phosphodiesterase type 5 inhibitors (e.g., sildenafil, tadalafil) or a guanylate cyclase stimulator (riociguat).

Direct head-to-head comparisons between individual medications are not available, but all of the PH-targeted medications are strongly recommended for the treatment of patients with pulmonary arterial hypertension and symptoms of NYHA functional classes II to IV who do not have vasodilator responsiveness. ${ }^{1}$ These recommendations are largely based on short (e.g., 12-16 weeks) placebo-controlled RCTs (Appendix 2) ${ }^{33-39}$ Intravenous epoprostenol is the only $\mathrm{PH}$-targeted medication that has shown improved survival for patients with advanced pulmonary arterial hypertension (in a 12-week RCT). ${ }^{39}$ Long-term RCT data are available for the endothelin receptor antagonist macitentan and the prostanoid receptor agonist selexipag, both of which reduced morbidity, including a decrease in risk of worsening $\mathrm{PH}$ and less frequent hospital admission. ${ }^{33,40}$ With regard to all other $\mathrm{PH}-$ targeted medications, evidence from uncontrolled open-label extension trials, single-centre case series and large multicentre registries also supports long-term clinical and functional benefits and suggests improved survival. ${ }^{41}$

The therapeutic decision regarding initial medical treatment of an individual patient is complex and requires an individualized approach by a clinical expert in PH. After careful consideration of the cause and severity of the pulmonary arterial hypertension, as well as the patient's demographic characteristics and comorbid illnesses, the physician and patient together select a PH-targeted medication on the basis of properties such as route, complexity, frequency and cost of administration, risk of drug-drug interactions and potential for tolerance of possible adverse effects, since all of the PH-targeted medications are effective. The most common approach to initial treatment of pulmonary arterial hypertension is a single oral targeted medica- tion. More complex parenteral prostacyclin analogue therapy (by infusion) is generally reserved for patients with progressive NYHA functional class III or IV pulmonary arterial hypertension. ${ }^{1}$

\section{Use of PH-targeted medications in a combination therapy approach}

It has been increasingly recognized that, for many patients with pulmonary arterial hypertension, treatment with a single oral $\mathrm{PH}$-targeted agent is associated either with an inadequate initial response or with eventual progression of $\mathrm{PH}$ and right ventricular failure. For such patients, a more aggressive approach, involving combination therapy, is recommended, on the basis of increasing strong evidence of the substantial long-term benefits of combining medications from different drug families to target multiple pathobiologic pathways. ${ }^{1,33,38}$ Furthermore, a recent long-term RCT showed for the first time that initial oral combination therapy with ambrisentan and tadalafil was more effective than monotherapy with either drug alone, reducing the combined risk of clinical failure (e.g., hospital admission, progression of pulmonary arterial hypertension) and unsatisfactory clinical response (hazard ratio [HR] 0.50, 95\% CI 0.35 0.72). ${ }^{42}$ Consistent benefit was observed, regardless of cause, NYHA functional class, age, geographic area and sex.

Some recent data support combination "triple therapy" using one agent from each of the three families of PH-targeted medications. For example, a small uncontrolled trial showed dramatic cardiopulmonary, functional and survival benefits with initial triple therapy (oral bosentan and sildenafil, intravenous epoprostenol) in 19 patients with severe NYHA class III or IV idiopathic pulmonary arterial hypertension and right ventricular failure. ${ }^{43}$ Moreover, in a recent large RCT $(n=1156)$, a prostanoid receptor agonist (selexipag) reduced the risk of progression and hospital admission (HR $0.60,95 \%$ CI $0.46-0.78) .{ }^{40}$ In a subgroup analysis relevant to triple oral therapy, the addition of selexipag offered similar benefit in patients already receiving background dual oral $\mathrm{PH}$-targeted therapy with a phosphodiesterase type 5 inhibitor and an endothelin receptor antagonist. ${ }^{40}$

\section{Monitoring}

Regardless of the initial treatment plan and despite initial treatment response, many patients have persistent moderate-to-severe pulmonary arterial hypertension and substantial right ventricular failure, which are associated with worse long-term prognosis. Although numerous putative prognostic markers have been identified, no single parameter adequately captures the complexity of 
the pathobiology and disturbed cardiopulmonary physiology of pulmonary arterial hypertension and resultant right ventricular failure. At diagnosis, certain patient characteristics predict worse survival, including male sex (odds ratio [OR] 0.84, 95\% CI 0.75-0.93), older age (3-yr survival $68 \%$ among patients $>65$ yr v. $83.3 \%$ among patients $18-65 \mathrm{yr} ; p<0.001)$ and subtype of pulmonary arterial hypertension (e.g., associated with connective tissue disease). ${ }^{41,44}$ More importantly, other parameters are predictive of poor survival after institution of PH-targeted therapy, including worse NYHA functional class (III or IV v. I or II), lower 6-minute walk distance and right ventricular failure with lower cardiac output or index. ${ }^{41,45}$ As such, one guideline strongly recommends regular comprehensive assessment using a composite panel of multiple markers to assess the severity of pulmonary arterial hypertension and right ventricular failure, to measure the response to therapy and to guide decisions related to intensification or change in therapy (Table 1). ${ }^{1}$

Table 1: Assessment of severity of pulmonary hypertension at baseline and during follow-up ${ }^{1}$

\begin{tabular}{|c|c|}
\hline Parameter & Goal \\
\hline \multicolumn{2}{|l|}{ Clinical assessment } \\
\hline NYHA functional class (I-IV) & Class I or II \\
\hline $\begin{array}{l}\text { Physical examination for RV failure (distension } \\
\text { of jugular vein, peripheral edema) }\end{array}$ & Minimal RV failure \\
\hline \multicolumn{2}{|l|}{ Exercise capacity } \\
\hline Distance on 6-min walk test & $>440 \mathrm{~m}$ \\
\hline \multicolumn{2}{|l|}{ Cardiopulmonary exercise testing } \\
\hline Peak $\mathrm{VO}_{2}$ & $>15 \mathrm{~mL} / \mathrm{min}$ per $\mathrm{kg}$ \\
\hline Ventilatory equivalent for $\mathrm{CO}_{2}$ & $<36$ \\
\hline \multicolumn{2}{|l|}{ RV imaging } \\
\hline Echocardiography (RVSP, RV size and function) & Normal or near normal \\
\hline $\begin{array}{l}\text { Cardiac magnetic resonance imaging (RV size } \\
\text { and function, cardiac output) }\end{array}$ & Normal or near normal \\
\hline \multicolumn{2}{|l|}{ Plasma biomarker } \\
\hline Brain natriuretic peptide & Normal \\
\hline \multicolumn{2}{|l|}{$\begin{array}{l}\text { Cardiopulmonary hemodynamics (by } \\
\text { right-heart catheterization) }\end{array}$} \\
\hline \multicolumn{2}{|l|}{ Measures of pulmonary hypertension } \\
\hline Mean pulmonary arterial pressure & Normal or near normal \\
\hline Pulmonary vascular resistance & Normal or near normal \\
\hline \multicolumn{2}{|l|}{ Measures of RV function } \\
\hline Right atrial pressure & $<8 \mathrm{~mm} \mathrm{Hg}$ \\
\hline Cardiac index & $\geq 2.5 \mathrm{~L} / \mathrm{min}$ per $\mathrm{m}^{2}$ \\
\hline Mixed venous $\mathrm{O}_{2}$ saturation & $>65 \%$ \\
\hline
\end{tabular}

\section{Lung transplant}

Despite the availability of many effective PHtargeted medications and increasing evidence for greater long-term survival, the prognosis for individual patients is uncertain. Double lung transplant remains an important final management option for patients with persistent or progressive NYHA functional class III or IV disease despite optimal medical therapy. Patients undergoing lung transplant can expect improved survival: $52 \%-75 \%$ at 5 years and $45 \%-66 \%$ at 10 years. ${ }^{46}$

\section{What is the optimal management of WHO group 4 CTEPH?}

The median 2- to 3-year survival rate among patients with untreated severe CTEPH is $10 \%-$ $20 \% .{ }^{47}$ Surgical pulmonary endarterectomy has not been evaluated in RCTs but is a potentially curative therapy that is strongly recommended as the treatment of choice for all eligible patients with CTEPH. ${ }^{1,3}$ This recommendation is based on several large, uncontrolled surgical series that reported marked improvements in pulmonary hemodynamics, clinical features, functional capacity and healthrelated quality of life, as well as greatly improved survival. ${ }^{48,49}$ For example, the world's largest CTEPH centre, in San Diego, reported cumulative 5- and 10-year survival rates of $82 \%$ and $75 \%$, respectively $(n=1410)$ after pulmonary endarterectomy. ${ }^{48}$ About $20 \%$ of patients have residual $\mathrm{PH}$ after pulmonary endarterectomy. ${ }^{50,51}$

Unfortunately, about one-third of patients with CTEPH are not candidates for pulmonary endarterectomy because of substantial medical comorbidities or the presence of chronic thromboembolic disease predominantly in small, peripheral pulmonary arteries that are not easily accessible for surgery. Given the tremendous benefit of pulmonary endarterectomy, the decision to not pursue a surgical approach for an individual patient should be made only at a centre with experience in the assessment of such patients, in collaboration with a surgeon with specific expertise. Balloon pulmonary artery angioplasty is a novel approach that may benefit patients with inoperable CTEPH, but it requires further study. ${ }^{1}$

In patients with inoperable CTEPH or residual $\mathrm{PH}$ after pulmonary endarterectomy, treatment with $\mathrm{PH}$-targeted medications is indicated. ${ }^{1,3}$ Riociguat is the only medication approved by Health Canada for the treatment of inoperable or residual CTEPH, on the basis of a single 16-week RCT that showed improvements in NYHA functional class (experienced by $18 \%$ of patients; $p<0.001$ ), 6 -minute walk distance (mean improvement $46 \mathrm{~m}, 95 \% \mathrm{CI}$ 
25-67 m), health-related quality of life ( $p<$ 0.001 ) and pulmonary hemodynamics (reduced pulmonary vascular resistance of 3.08 Wood units, 95\% CI 2.38-3.79 Wood units). ${ }^{52}$ Uncontrolled data suggest continued long-term clinical and functional benefits with such treatment. ${ }^{53}$

\section{Conclusion}

Despite the availability of several effective therapeutic options, especially for patients with WHO group 1 pulmonary arterial hypertension and WHO group 4 CTEPH, many patients with $\mathrm{PH}$ are still at risk of substantial morbidity and premature mortality. Clinical vigilance and a systematic diagnostic approach are critical to ensuring accurate and prompt diagnosis to allow patients to maximally benefit from available therapies.

\section{References}

1. Galiè N, Humbert M, Vachiery J, et al. 2015 ESC/ERS guidelines for the diagnosis and treatment of pulmonary hypertension: the Joint Task Force for the Diagnosis and Treatment of Pulmonary Hypertension of the European Society of Cardiology (ESC) and the European Respiratory Society (ERS): endorsed by: Association for European Paediatric and Congenital Cardiology (AEPC), International Society for Heart and Lung Transplantation (ISHLT). Eur Respir J 2015;46:903-75.

2. Benza RL, Miller DP, Barst RJ, et al. An evaluation of long-term survival from time of diagnosis in pulmonary arterial hypertension from the REVEAL registry. Chest 2012;142:448-56.

3. Mehta S, Helmersen D, Provencher S, et al. Diagnostic evaluation and management of chronic thromboembolic pulmonary hypertension: a clinical practice guideline. Can Respir J 2010;17:301-34.

4. Simonneau G, Galiè N, Rubin L, et al. Clinical classification of pulmonary hypertension. J Am Coll Cardiol 2004;43:5S-12S.

5. Tuder RM, Archer SL, Dorfmüller P, et al. Relevant issues in the pathology and pathobiology of pulmonary hypertension. J Am Coll Cardiol 2013;62:D4-12.

6. Ghio S, Gavazzi A, Campana C, et al. Independent and additive prognostic value of right ventricular systolic function and pulmonary artery pressure in patients with chronic heart failure. J Am Coll Cardiol 2001;37:183-8.

7. Chaouat A, Bugnet AS, Kadaoui N, et al. Severe pulmonary hypertension and chronic obstructive pulmonary disease. Am J Respir Crit Care Med 2005;172:189-94.

8. Oswald-Mammosser M, Weitzenblum E, Quoix E, et al. Prognostic factors in COPD patients receiving long-term oxygem therapy. Importance of pulmonary artery pressure. Chest 1995;107:1193-8.

9. Gerges C, Gerges M, Lang MB, et al. Diastolic pulmonary vascular pressure gradient: a predictor of prognosis in "out-ofproportion" pulmonary hypertension. Chest 2013;143:758-66.

10. American College of Chest Physicians and American Thoracic Society. Five things physicians and patients should question. In: Choosing Wisely: an initiative of the ABIM Foundation. Philadelphia: ABIM Foundation; 2013. Available: www.choosingwisely. org/societies/american-college-of-chest-physicians-and-american -thoracic-society/ (accessed 2016 Mar. 8)

11. Becattini C, Agnelli G, Pesavento R, et al. Incidence of chronic thromboembolic pulmonary hypertension after a first episode of pulmonary embolism. Chest 2006;130:172-5.

12. Pengo V, Lensing AW, Prins MH, et al. Incidence of thromboembolic pulmonary hypertension after pulmonary embolism. N Engl J Med 2004;350:2257-64.

13. Klok FA, Dzikowska-Diduch O, Kostrubiec M, et al. Derivation of a clinical prediction score for chronic thromboembolic pulmonary hypertension after acute pulmonary embolism. J Thromb Haemost 2016;14:121-8.

14. Pepke-Zaba J, Delcroix M, Lang I, et al. Chronic thromboembolic pulmonary hypertension (CTEPH): results from an international prospective registry. Circulation 2011;124:1973-81.

15. Bonham CA, Oldham JM, Gomberg-Maitland M, et al. Prostacyclin and oral vasodilator therapy in sarcoidosis-associated pulmonary hypertension: a retrospective case series. Chest 2015;148:1055-62.
16. Machado RF, Barst RJ, Yovetich NA, et al. Hospitalization for pain in patients with sickle cell disease treated with sildenafil for elevated TVR and low exercise capacity. Blood 2011;118: 855-64.

17. Colman R, Whittingham $\mathrm{H}$, Tomlinson $\mathrm{G}$, et al. Utility of the physical examination in detecting pulmonary hypertension. A mixed methods study. PLoS One 2014;9:e108499.

18. McGoon MD, Benza RL, Escribano-Subias P, et al. Pulmonary hypertension: epidemiology and registries. J Am Coll Cardiol 2013;62:D51-9.

19. Khanna D, Gladue H, Channick R, et al. Recommendations for screening and detection of connective tissue disease-associated pulmonary arterial hypertension. Arthritis Rheum 2013;65: 3194-201.

20. Currie PJ, Seward JB, Chan KL, et al. Continuous wave Doppler determination of right ventricular pressure: a simultaneous Doppler-catheterization study in 127 patients. J Am Coll Cardiol 1985;6:750-6.

21. Testani JM, St. John Sutton MG, Wiegers SE, et al. Accuracy of non-invasively determined pulmonary artery systolic pressure. Am J Cardiol 2010;105:1192-7.

22. Rich JD, Shah SJ, Swamy RS, et al. Inaccuracy of Doppler echocardiographic estimates of pulmonary artery pressures in patients with pulmonary hypertension. Chest 2011;139:988-93.

23. Fisher MR, Forfia PR, Chamera E, et al. Accuracy of Doppler echocardiography in the hemodynamic assessment of pulmonary hypertension. Am J Respir Crit Care Med 2009;179:615-21.

24. Humbert M, Sitbon O, Chaouat A, et al. Pulmonary arterial hypertension in France: results from a national registry. Am J Respir Crit Care Med 2006;173:1023-30.

25. Sitbon O, Humbert M, Jaïs X, et al. Long-term response to calcium channel blockers in idiopathic pulmonary arterial hypertension. Circulation 2005;111:3105-11.

26. Tunariu N, Gibbs SJ, Win Z, et al. Ventilation-perfusion scintigraphy is more sensitive than multidetector CTPA in detecting chronic thromboembolic pulmonary disease as a treatable cause of pulmonary hypertension. J Nucl Med 2007;48:680-4

27. Chan L, Chin LM, Kennedy M, et al. Benefits of intensive treadmill training on cardiorespiratory function and quality of life in patients with pulmonary hypertension. Chest 2013;143:333-43.

28. Mereles D, Ehlken N, Kreuscher S, et al. Exercise and respiratory training improve exercise capacity and quality of life in patients with severe chronic pulmonary hypertension. Circulation 2006;114:1482-9.

29. Johnson SR, Mehta S, Granton JT. Anticoagulation in pulmonary arterial hypertension: a qualitative systematic review. Eur Respir J 2006;28:999-1004.

30. Jaïs X, Olsson KM, Barbera JA, et al. Pregnancy outcomes in pulmonary arterial hypertension in the modern management era. Eur Respir J 2012;40:881-5.

31. Thorne S, Nelson-Piercy C, MacGregor AJ, et al. Pregnancy and contraception in heart disease and pulmonary hypertension. J Fam Plann Reprod Health Care 2006;32:75-81.

32. Archer SL, Weir EK, Wilkins MR. Basic science of pulmonary arterial hypertension for clinicians: new concepts and experimental therapies. Circulation 2010;121:2045-66.

33. Pulido T, Adzerikho I, Channick RN, et al. Macitentan and morbidity and mortality in pulmonary arterial hypertension. N Engl J Med 2013;369:809-18.

34. Channick RN, Simonneau G, Sitbon O, et al. Effects of the dual endothelin-receptor antagonist bosentan in patients with pulmonary hypertension: a randomized placebo-controlled study. Lancet 2001;358:1119-23.

35. Galiè N, Olschewski H, Oudiz RJ, et al. Ambrisentan for the treatment of pulmonary arterial hypertension. Results of the Ambrisentan in Pulmonary Arterial Hypertension, Randomized, Double-Blind, Placebo-Controlled, Multicenter, Efficacy (ARIES) Study 1 and Study 2. Circulation 2008;117:3010-9.

36. Galiè N, Ghofrani HA, Torbicki A, et al. Sildenafil citrate for pulmonary arterial hypertension. N Engl J Med 2005;353:2148-57.

37. Galiè N, Brundage BH, Ghofrani HA, et al. Tadalafil therapy for pulmonary arterial hypertension. Circulation 2009;119:2894-903.

38. Ghofrani HA, Galiè N, Grimminger F, et al. Riociguat for the treatment of pulmonary arterial hypertension. N Engl J Med 2013; 369:330-40.

39. Barst RJ, Rubin LJ, Long WA, et al. A comparison of continuous intravenous epoprostenol (prostacyclin) with conventional therapy for primary pulmonary hypertension. $N$ Engl J Med 1996;334: 296-301.

40. Sitbon O, Channick R, Chin KM, et al. Selexipag for the treatment of pulmonary arterial hypertension. N Engl J Med 2015;373: 2522-33.

41. Farber HW, Miller DP, Poms AD, et al. Five-year outcome of patients enrolled in REVEAL registry. Chest 2015;148:1043-54. 
42. Galiè N, Barbera JA, Frost AE, et al. Initial use of ambrisentan plus tadalafil in pulmonary arterial hypertension. $N$ Engl $J$ Med 2015;373:834-44.

43. Sitbon O, Jaïs X, Savale L, et al. Upfront triple combination therapy in pulmonary arterial hypertension: a pilot study. Eur Respir J 2014;43:1691-7.

44. Hoeper MM, Huscher D, Ghofrani HA, et al. Elderly patients diagnosed with idiopathic pulmonary arterial hypertension: results of the COMPERA registry. Int J Cardiol 2013; 168:871-80.

45. Nickel N, Golpon H, Greer M, et al. The prognostic impact of follow-up assessments in patients with pulmonary arterial hypertension. Eur Respir J 2012;39:589-96.

46. de Perrot M, Granton JT, McRae K, et al. Outcome of patients with pulmonary arterial hypertension referred for lung transplantation: a 14-year single-center experience. J Thorac Cardiovasc Surg 2012;143:910-8

47. Lewczuk J, Pisko P, Jagas J, et al. Prognostic factors in medically treated patients with chronic pulmonary embolism. Chest 2001;119:818-23.

48. Madani MM, Auger WR, Pretorius V, et al. Pulmonary endarterectomy: recent changes in a single institutions experience of more than 2,700 patients. Ann Thorac Surg 2012;94:97-103.

49. Mayer E, Jenkins D, Lindner J, et al. Surgical management and outcome of patients with chronic thromboembolic pulmonary hypertension: results from an international registry. $J$ Thorac Cardiovasc Surg 2011;141:702-10.

50. Skoro-Sajer N, Marta G, Gerges C, et al. Surgical specimens, haemodynamics and long-term outcomes after pulmonary endarterectomy. Thorax 2014;69:116-22.

51. Freed DH, Thomson BM, Berman M, et al. Survival after pulmonary thromboendarterectomy: effect of residual pulmonary hypertension. J Thorac Cardiovasc Surg 2011;141:383-7.

52. Ghofrani HA, D'Armini AM, Grimminger F, et al. Riociguat for the treatment of chronic thromboembolic pulmonary hypertension. N Engl J Med 2013;369:319-29.

53. Simonneau G, D'Armini AM, Ghofrani HA, et al. Riociguat for the treatment of chronic thromboembolic pulmonary hypertension: a long-term extension study (CHEST-2). Eur Respir $J$ 2015;45:1293-302.

Competing interests: Nathan Hambly has received consultancy honoraria from Actelion Pharmaceuticals and BoehringerIngelheim Canada, and honoraria and payment of travel expenses from Hoffmann-La Roche Canada. Sanjay Mehta has received consultancy and speaker fees from Actelion, Bayer, GlaxoSmithKline; research grant support from Actelion, the Heart and Stroke Foundation of Canada (Ontario branch) and the Ontario Thoracic Society; and investigator fees for participation in pharmaceutical clinical trials from Actelion, Bayer, Gilead, Ikaria, Lilly and United Therapeutics. He is also chair of the board of directors of the Pulmonary Hypertension Association of Canada. No other competing interests were declared.

Affiliations: Firestone Institute for Respiratory Health (Hambly), Division of Respirology, McMaster University, Hamilton, Ont.; Southwest Ontario Pulmonary Hypertension Clinic, Division of Respirology (Alawfi, Mehta), London Health Sciences Centre, London, Ont.; Schulich School of Medicine (Alawfi, Mehta), University of Western Ontario, London, Ont.

Contributors: Nathan Hambly was involved in conception and design of the review, literature search, abstract review, full-text review, data abstraction, and drafting and editing of the manuscript. Fahad Alawfi was involved in design of the review, literature search, abstract review, full-text review, data abstraction and manuscript editing. Sanjay Mehta was involved in conception and design of the review, literature search, full-text review, data abstraction, and drafting and editing of the manuscript. All of the authors gave final approval of the version to be published and agreed to act as guarantors of the work. 